\title{
The role of pirfenidone in the treatment of idiopathic pulmonary fibrosis
}

\author{
Vincent Cottin \\ From AIR: Advancing IPF Research. Working together to translate IPF research into practice \\ Berlin, Germany. 4-5 November 2011
}

\begin{abstract}
Idiopathic pulmonary fibrosis (IPF) is a progressive disease, with a median survival time of $2-5$ years. The search for effective treatment has involved numerous clinical trials of investigational agents without significant success.

However, in 2011, pirfenidone was the first drug to be approved for the treatment of IPF in Europe. Four key

clinical trials supported the efficacy and tolerability of pirfenidone.

In the two recently published Phase III CAPACITY trials evaluating pirfenidone (studies 004 and 006), patients with mild-to-moderate IPF were treated with pirfenidone or placebo. Study 004 and pooled analysis of primary

endpoint data from both studies showed that pirfenidone significantly reduced decline in percent-predicted forced vital capacity (FVC) compared with placebo $(p<0.005)$. Evidence of beneficial effects of pirfenidone treatment was also observed with regard to several secondary endpoints. Pirfenidone was generally well tolerated, with the most common side effects being gastrointestinal and photosensitivity. Data from the RECAP extension phase of the CAPACITY studies, where patients were treated with pirfenidone for up to three years, further support the manageable tolerability profile of pirfenidone. The efficacy data, coupled with long-term safety data, provide further evidence of a clinically-meaningful treatment effect with pirfenidone in patients with IPF.
\end{abstract}

\section{Background}

Idiopathic pulmonary fibrosis (IPF) is a debilitating disease, occurring predominantly in adults of around 60-75 years of age,[1] with an estimated prevalence of IPF of 1.6-1.7/10,000.[2-4] The disease course is progressive and ultimately fatal, with a median survival of $2-5$ years $[5,6]$ - worse than a number of malignancies [7]. Progressive deterioration of pulmonary function occurs, which increasingly limits the patient's ability to perform normal physical activities.[8] The speed and extent of this deterioration is often unpredictable,[9] with patients who generally appear to have stable disease often suffering episodes of acute exacerbation.[10,11]

A decline in both relative and absolute changes in the forced vital capacity (FVC) has been shown consistently to predict mortality in patients with IPF.[12-14] A decline in FVC of $10 \%$ or more in a six-month period is associated

\footnotetext{
Correspondence: vincent.cottin@chu-lyon.fr Hospices Civils de Lyon, Hôpital Louis Pradel, Service de pneumologie Centre de référence national des maladies pulmonaires rares, Université Claude Bernard Lyon 1, Lyon, France
}

with a nearly five-fold increase in the risk of mortality. [12-15] However, whilst serial FVC measurements are a validated marker of chronic disease progression, and frequently used as an endpoint in clinical trials,[16-18] it is not a proven surrogate for mortality. Nevertheless, agents that attenuate the decline in FVC are anticipated to play an important role in IPF management.

Pirfenidone has been shown to reduce the decline in FVC in patients with IPF. This is an orally available drug that exhibits anti-fibrotic and anti-inflammatory properties in vitro and in vivo.[19-23] There is evidence to show that pirfenidone diminishes fibroblast proliferation, secretion of the fibrosis-associated proteins and cytokines, biosynthesis and accumulation of extracellular matrix as well as accumulation of inflammatory cells and tumour necrosis factor- $\alpha$ synthesis.[19-23]

\section{Clinical trials of pirfenidone in patients with IPF}

Following evaluation in Phase II and Phase III clinical trials in patients with IPF.[24-26], pirfenidone was approved by the European Commission in February 2011

\section{Biomed Central}


Pirfenidone is indicated for the treatment of patients with mild-to-moderate IPF. Mild-to-moderate disease was characterised in two pivotal Phase III studies using the following functional criteria: FVC $\geq 50 \%$ of predicted value, carbon monoxide diffusing capacity $\left(\mathrm{DL}_{\mathrm{CO}}\right) \geq 35 \%$ of predicted value and a 6 minute walk test (6MWT) distance of $\geq 150 \mathrm{~m}$.[26]

Based on the positive results of a Phase II study by Azuma et al.,[24] a multicentre, double-blind, placebo-controlled, randomised Phase III clinical trial was conducted in Japan to determine the efficacy and safety of pirfenidone in 275 patients with IPF.[25] Patients were randomised to pirfenidone $1800 \mathrm{mg}$ per day, pirfenidone $1200 \mathrm{mg}$ per day or placebo using a 2:1:2 ratio, with 267 patients evaluated for the efficacy of pirfenidone. The dose of pirfenidone was increased in a stepwise manner up to the treatment dose over four weeks. The primary endpoint was vital capacity (VC) from baseline to 52 weeks. This was changed before unblinding of the study (it was previously the lowest arterial oxygen saturation measured by pulse oximetry $\left(\mathrm{SpO}_{2}\right)$ during the six-minute steady state exercise test). This decision was based on the evolved knowledge of assessment with objective measurements in IPF, along with the lack of validation of the steady state exercise test and problems in reproducing $\mathrm{SpO}_{2}$ measurements. Secondary endpoints included progression-free survival (this was defined as time until the first progressive event, i.e. either decrease in $\mathrm{VC}$ of $>10 \%$ or death) and change in the lowest $\mathrm{SpO}_{2}$ during the six-minute steady state exercise test.[25]

Statistically significant differences were observed between the pirfenidone 1,800 $\mathrm{mg}$ group and the placebo group for both the primary and secondary endpoints. Pirfenidone was associated with a $44 \%$ reduction in the $\mathrm{VC}$ decline compared with placebo $(-0.09 \mathrm{~L}$ vs $-0.16 \mathrm{~L}$; $\mathrm{p}=0.0416$ ), along with a significant increase in progressionfree survival $(\mathrm{p}=0.0280)$.[25] Pirfenidone was relatively well tolerated, the most common adverse event observed with pirfenidone was photosensitivity, which was rated as mild in the majority of patients,[25] and has previously been documented as a side effect associated with pirfenidone treatment.[25,27] The data from this Phase III trial led to the approval of pirfenidone in Japan in 2008 for the treatment of IPF.

Two concurrent, similarly designed Phase III trials (studies 004 and 006, the "CAPACITY" studies), were conducted at 110 sites across North America, Australia and 11 European countries. Both were randomised, doubleblind, placebo-controlled studies with treatment periods of 72 weeks.[26] The studies were designed to confirm the results of a Phase II study suggesting that pirfenidone reduced the deterioration in lung function in patients with IPF.[24]

Patients aged $40-80$ years with mild-to-moderate IPF, diagnosed within the previous 48 months, were randomised to treatment with either oral pirfenidone or oral placebo. In study 004, patients were assigned to pirfenidone 2403 $\mathrm{mg} /$ day, $1197 \mathrm{mg} /$ day or placebo in a 2:1:2 ratio. In study 006 , patients were assigned to pirfenidone $2403 \mathrm{mg} /$ day or placebo in a 1:1 ratio. Pirfenidone was administered with food three times a day and increased to the full dose (2403 $\mathrm{mg} /$ day) over two weeks. The lower dose of $1197 \mathrm{mg} /$ day was included in study 004 to investigate any dose-response effect in terms of efficacy.[26]

The primary endpoint of both studies was change in percentage predicted FVC from baseline to week 72 . Secondary endpoints at week 72 included categorical decline in FVC $\geq 10 \%$, progression-free survival (time to confirmed $\geq 10 \%$ decline in percentage predicted FVC, $\geq 15 \%$ decline in percentage predicted $\mathrm{DL}_{\mathrm{CO}}$ or death), mean change in $6 \mathrm{MWT}$ distance, mean change in percentage predicted $\mathrm{DL}_{\mathrm{CO}}$, mean change in dyspnoea score, mean percentage change in worst $\mathrm{SpO}_{2}$ during 6MWT and time to worsening of IPF. Mortality was included as an exploratory endpoint. Categorical change in high-resolution computed tomographic (HRCT)-diagnosed fibrosis was included as a secondary endpoint in study 006.[26]

In study 004, pirfenidone $2403 \mathrm{mg} /$ day significantly reduced mean decline from baseline to week 72 in percentage predicted FVC, compared with placebo $(-8.0 \%[ \pm 16.5]$ vs $-12.4 \%[ \pm 18.5]$, respectively; $\mathrm{p}=0.001)$, as well as the proportion of patients with FVC decline $\geq 10 \%$. This treatment effect was evident between weeks 24 and 72 . A pirfenidone effect was confirmed $(\mathrm{p}=0.0007)$ after repeat-measured analysis of the predicted percentage change in FVC across all assessment timepoints. In the pirfenidone $1197 \mathrm{mg} /$ day group, the primary endpoint outcomes were intermediate to those of the $2403 \mathrm{mg}$ /day pirfenidone and placebo groups.[26]

While the difference between groups in mean FVC change at Week 72 was not significant in Study 006 (-9.0\% [SD 19.6] and -9.6\% [19.1] respectively, $\mathrm{p}=0.501)$, this may have been due to a lower than expected rate of FVC decline in Study 006 after 1 year in the placebo group.[26] Moreover, a consistent pirfenidone effect was apparent until Week $48(\mathrm{p}=0.005)$ and also in an analysis of all study timepoints $(\mathrm{p}=0.007)$. Thus, the data from this study generally supported those from Study 004, with a positive treatment effect of pirfenidone being observed at all timepoints from weeks 12 to 48 but not at later time points.[26]

The effect of pirfenidone treatment on percentage predicted FVC at week 72 was supported by pooled analysis of data from both studies. Mean decline in percentage predicted FVC was $-8.5 \%$ and $-11.0 \%$ for the pirfenidone 2403 $\mathrm{mg} /$ day and placebo groups, respectively $(\mathrm{p}=0.005)$. Additionally, the pooled analysis demonstrated a $30 \%$ reduction in the percentage of patients with a categorical decline in $\mathrm{FVC} \geq 10 \%$ at week $72(\mathrm{p}=0.003)$, a $31 \%$ reduction 
in the mean decline in 6MWT distance $(\mathrm{p}>0.001)$ and a $26 \%$ reduction in the risk of death or disease progression (HR 0.74; 95\% CI 0.57, 0.96; $\mathrm{p}=0.025$ ).[26]

Exploratory analysis of mortality data revealed that the hazard ratios for all-cause mortality $(\mathrm{p}=0.315)$ and mortality related to IPF at any time during the study $(\mathrm{p}=0.117)$, although not significant, numerically favoured pirfenidone over placebo. This was also the case with on-treatment IPF-related mortality, which occurred in $3 \%$ of patients treated with pirfenidone and $7 \%$ of those given placebo $(\mathrm{p}=0.03)$.[26]

\section{Cochrane meta-analysis of treatment effect}

Meta-analyses performed by the Cochrane Collaboration, published in 2010, investigated the treatment effect of pirfenidone using data from the clinical trials performed to date. Data from the two Japanese studies were eligible for a meta-analysis as they both included the endpoint of absolute change in VC.[28] A statistically significant difference was observed in terms of decline in $\mathrm{VC}$ in favour of pirfenidone, underlining the beneficial effect of pirfenidone on the change in VC compared to baseline. As progression-free survival was also used as an endpoint in the Phase III study by Taniguchi et al,[25] it was possible to combine the data from this study and perform a metaanalysis with data from the CAPACITY studies. The overall result of this meta-analysis suggested that pirfenidone reduced the risk of disease progression by $30 \%$ (HR $0.70,95 \%$ CI 0.56 to 0.88 ) in patients with IPF.[28]

\section{Tolerability in patients with IPF}

Regarding safety, pirfenidone was shown to be generally well tolerated at the $2403 \mathrm{mg} /$ day dose in the CAPACITY studies.[26] There was no significant difference in the number of patients experiencing serious treatment-emergent adverse events between the pirfenidone (pooled data) and placebo groups (33\% and $31 \%$ respectively). The majority of patients treated with pirfenidone $2403 \mathrm{mg} /$ day experienced at least one treatment-emergent adverse event, with the most common adverse events being gastrointestinal, skin disorders and dizziness. These adverse events were consistent with the known safety profile of pirfenidone and were usually mild to moderate in severity.[24] Adverse events leading to discontinuation occurred in 15\% of pirfenidonetreated patients and $9 \%$ of placebo-treated patients. The most common cause of study discontinuation was IPF (3\% of patients in each group). The only other causes of treatment discontinuation in the pooled pirfenidone group was nausea (1\%) and rash (1\%).[26]

An extension phase of the CAPACITY studies (called RECAP) was designed to assess the safety of pirfenidone beyond the duration of the Phase III studies. At Week 72 of the RECAP extension study, patients had been treated with pirfenidone for a mean duration of 2.9 years (range, 1-4). A number of patients $(n=114)$ had been treated at the full dose for at least three years. Data from the RECAP extension study confirm the tolerability of pirfenidone.[29]

Common adverse events and those considered treatment-emergent occurred in a very similar proportion of patients to those reported during the CAPACITY studies. Almost all patients (98\%) reported at least one treatmentemergent adverse event, compared with $99 \%$ of patients in the CAPACITY studies across both treatment arms. Similar proportions of patients in RECAP experienced serious adverse events to those in the CAPACITY studies (33\% vs 33\%). The incidence of common adverse events was very similar to that observed in the CAPACITY studies, and were generally mild to moderate in severity. No new or unexpected safety issues were observed.[29]

Rash or photosensitivity occurred in fewer patients from the RECAP extension study than in the CAPACITY studies (20\% vs $44 \%$ ). This was more common among patients initiating treatment with pirfenidone compared with those who were continuing with treatment ( $28 \%$ vs $12 \%)$. These data provide further important information on treatment with pirfenidone and demonstrate its tolerability.[29]

\section{Conclusions}

There has been a considerable advance in terms of research into prognostic factors, with decline in \% FVC being found to be a predictor of mortality risk. Until recently, therapeutic developments had lagged somewhat, but the increase in the number of clinical trials has been encouraging. However, many of these trials either failed to show significant treatment benefit against this challenging disease. Further studies are required to evaluate the potential benefit of other agents, such as $\mathrm{N}$-acetylcysteine (NAC) [30] and nintedanib (BIBF 1120),[31] in IPF. The first major step forward has been the European approval of pirfenidone for patients with mild-to-moderate IPF. Pirfenidone has demonstrated statistically-significant and clinically-meaningful effects in clinical trials. Overall, pirfenidone provides a significant treatment benefit for patients with IPF and represents an appropriate option as first-line therapy for these patients.

\section{Abbrevations}

\section{Competing interests}

Vincent Cottin has received fees for speaking from Intermune, Boehringer Ingelheim, and Actelion, and has participated as a member of steering committees, a member of data safety monitoring boards or as an investigator to clinical trials sponsored by Actelion, Boehringer Ingelheim, Gilead, and Intermune Inc.

\section{Acknowledgements}

The author thanks C. Trenam, I. Mandic and M. Smith of IntraMed

Communications for editorial assistance in the preparation of the manuscript. Development of this article was supported by InterMune AG. 


\section{Declarations}

This article has been published as part of Respiratory Research Volume 14 Supplement 1, 2013:IPF in 2011 - Key updates on guidelines and therapeutics. The full contents of the supplement are available online at http://respiratory-research.com/supplements/14/S1. Publication of this supplement was supported by IntraMed Communications with funding from InterMune, AG. InterMune is the manufacturer of pirfenidone, a product mentioned in this article. The supplement originates from presentations given at the "AlR Event: Advancing IPF Research. Working together to translate IPF research into practice" held in Berlin in November 2011. The publication was proposed by IntraMed Communications and developed in consultation with the journal. All articles in the supplement have undergone the journal's standard peer review process.

Published: 16 April 2013

\section{References}

1. Raghu G, Weycker D, Edelsberg J, et al: Incidence and prevalence of idiopathic pulmonary fibrosis. Am J Respir Crit Care Med 2006, 174:810-816.

2. Hodgson U, Laitinen T, Tukiainen P: Nationwide prevalence of sporadic and familial idiopathic pulmonary fibrosis: evidence of founder effect among multiplex families in Finland. Thorax 2002, 57:338-342.

3. Orphanet: Orphanet Report Series. Rare Diseases collection. Prevalence of rare diseases: Bibliographic data. 2011, Number 1 [http://www. orphanet.net].

4. Nalysnyk L, Cid-Ruzafa J, Rotella P, Esser D: Incidence and prevalence of idiopathic pulmonary fibrosis: review of the literature. Eur Respir Rev 2012, 21(126):355-61.

5. Collard HR, King TE Jr., Bartelson BB, et al: Changes in clinical and physiologic variables predict survival in idiopathic pulmonary fibrosis. Am J Respir Crit Care Med 2003, 168(5):538-542.

6. Kim DS, Collard HR, King TE: Classification and natural history of the idiopathic interstitial pneumonias. Proc Am Thorac Soc 2006, 3(4):285-292.

7. Vancheri C, Failla M, Crimi N, Raghu G: Idiopathic pulmonary fibrosis: a disease with similarities and links to cancer biology. Eur Respir J 2010, 35:496-504.

8. American Thoracic Society/European Respiratory Society International Multidisciplinary Consensus Classification of the Idiopathic Interstitial Pneumonias. Am J Respir Care Med 2002, 165:277-304.

9. Nathan $\mathrm{SD}$, du Bois RM: Idiopathic pulmonary fibrosis trials: recommendations for the jury. Eur Respir J 2011, 38:1002-1004

10. Song JW, Hong SB, Lim CM, et al: Acute exacerbation of idiopathic pulmonary fibrosis: incidence, risk factors and outcome. Eur Respir J 2011, 37:356-363.

11. Valeyre $D$ : Towards a better diagnosis of idiopathic pulmonary fibrosis. Eur Respir Rev 2011, 20:108-113.

12. du Bois RM, Weycker D, Albera C, et al: Forced vital capacity in patients with idiopathic pulmonary fibrosis: test properties and minimal clinically important difference. Am J Respir Crit Care Med 2011, 184(12):1382-9.

13. Du Bois RM, Weycker D, Albera C, et al: Ascertainment of individual risk of mortality for patients with idiopathic pulmonary fibrosis. Am J Respir Crit Care Med 2011, 184:459-466.

14. Richeldi L, Ryerson CJ, Lee JS, et al: Interstitial lung disease: Original article: Relative versus absolute change in forced vital capacity in idiopathic pulmonary fibrosis. Thorax 2012, 67:407-11.

15. Flaherty KR, Mumford JA, Murray $S$, et al: Prognostic implications of physiologic and radiographic changes in idiopathic interstitial pneumonia. Am J Respir Crit Care Med 2003, 168:543-548.

16. Raghu G, Collard HR, Egan JJ, et al: An official ATS/ERS/ALAT statement: Idiopathic pulmonary fibrosis: Evidence-based guidelines for diagnosis and management. Am J Respir Crit Care Med 2011, 183:788-824.

17. Wells AU, Behr J, Costabel U, Cottin V, Poletti V, Richeldi L: Hot of the breath: Mortality as a primary end-point in IPF treatment trials: the best is the enemy of the good. Thorax 2012, 67(11):938-40,

18. du Bois RM, Nathan SD, Richeldi L, Schwarz MI, Noble PW: Idiopathic pulmonary fibrosis: lung function is a clinically meaningful endpoint for phase III trials. Am J Respir Crit Care Med 2012, 86(8):712-5.

19. Schaefer CJ, Ruhrmund DW, Pan L, et al: Antifibrotic activities of pirfenidone in animal models. Eur Respir Rev 2011, 20:85-97.

20. lyer SN, Gurujeyalakshmi G, Giri SN: Effects of pirfenidone on transforming growth factor-beta gene expression at the transcriptional level in bleomycin hamster model of lung fibrosis. J Pharmacol Exp Ther 1999, 291:367-373.

21. Gurujeyalakshmi G, Hollinger MA, Giri SN: Pirfenidone inhibits PDGF isoforms in bleomycin hamster model of lung fibrosis at the translational level. Am J Physiol 1999, 276:311-318.

22. Iyer SN, Gurujeyalakshmi G, Giri SN: Effects of pirfenidone on procollagen gene expression at the transcriptional level in bleomycin hamster model of lung fibrosis. J Pharmacol Exp Ther 1999, 289:211-218.

23. Oku H, Shimizu T, Kawabata T, et al: Antifibrotic action of pirfenidone and prednisolone: different effects on pulmonary cytokines and growth factors in bleomycin-induced murine pulmonary fibrosis. Eur J Pharmacol 2008, 590:400-408

24. Azuma A, Nukiwa T, Tsuboi E, et al: Double-blind, placebo-controlled trial of pirfenidone in patients with idiopathic pulmonary fibrosis. Am J Respi Crit Care Med 2005, 171:1040-1047.

25. Taniguchi $\mathrm{H}$, Ebina $\mathrm{M}$, Kondoh $\mathrm{Y}$, et al: Pirfenidone in idiopathic pulmonary fibrosis. Eur Respir J 2010, 35:821-829.

26. Noble PW, Albera C, Bradford WZ, et al: Pirfenidone in patients with idiopathic pulmonary fibrosis (CAPACITY): two randomised trials. Lancet 2011, 377:1760-1769.

27. Raghu G, Johnson WC, Lockhart D, Mageto Y: Treatment of idiopathic pulmonary fibrosis with a new antifibrotic agent, pirfenidone. Am J Respir Crit Care Med 1999, 159:1061-1069.

28. Spagnolo P, Del Giovane C, Luppi F, et al: Non-steroid agents for idiopathic pulmonary fibrosis (Review). Cochrane Database Syst Rev 2010, 9:CD003134

29. Costabel U, Albera C, Cohen A, et al: The long-term safety of pirfenidone in patients with idiopathic pulmonary fibrosis (IPF): Interim data from the RECAP extension study. Presented at The European Respiratory Society Annual Congress 2011, Abstract.

30. Raghu G, Anstrom KJ, King TE Jr, Lasky JA, Martinez FJ: Idiopathic Pulmonary Fibrosis Clinical Research Network, Prednisone, azathioprine, and N-acetylcysteine for pulmonary fibrosis. N Engl J Med 2012, 366(21):1968-77.

31. Richeldi $L$, Costabel $U$, Selman $M$, et al: Efficacy of a tyrosine kinase inhibitor in idiopathic pulmonary fibrosis. N Engl J Med 2011, 365:1079-1087.

\section{doi:10.1186/1465-9921-14-S1-S5}

Cite this article as: Cottin: The role of pirfenidone in the treatment of idiopathic pulmonary fibrosis. Respiratory Research 2013 14(Suppl 1):S5.

\section{Submit your next manuscript to BioMed Central and take full advantage of:}

- Convenient online submission

- Thorough peer review

- No space constraints or color figure charges

- Immediate publication on acceptance

- Inclusion in PubMed, CAS, Scopus and Google Scholar

- Research which is freely available for redistribution 